\title{
The importance of controlling for the acute-phase response in the population-based assessment of vitamin A status: a study in children of pre-school age in Uganda
}

\author{
Rhona Baingana ${ }^{1, *}$, Dennis Matovu-Kasozi ${ }^{1}$ and Dean Garrett ${ }^{2}$ \\ 'Department of Biochemistry, Makerere University, PO Box 7062, Kampala, Uganda: ${ }^{2}$ Program for Appropriate \\ Technology in Health (PATH), Seattle, WA, USA
}

Submitted 19 November 2011: Final revision received 24 July 2012: Accepted 7 August 2012: First published online 1 October 2012

\begin{abstract}
Objective: To improve estimates of vitamin A deficiency in children of pre-school age in the 2006 Uganda Demographic and Health Survey (UDHS 2006).

Design: A cross-sectional study in which dried blood spot samples were analysed for C-reactive protein (CRP). Retinol-binding protein (RBP) had previously been analysed using a commercial enzyme immunoassay.

Setting: A population-based study in Uganda.

Subjects: A systematically selected subset of the dried blood spot samples collected from children aged 6-59 months for UDHS 2006. Children were categorized into 'normal CRP' (Group A) and 'raised CRP' (Group B) using a CRP cut-off of $5 \mathrm{mg} / \mathrm{l}$. A correction factor was calculated to adjust the Group B RBP values for the influence of the acute-phase response.

Results: Geometric mean CRP was $6 \cdot 2$ (95\% CI 5·5, 7•0) mg/1, $1 \cdot 6$ (95\% CI 1·5, 1·8) $\mathrm{mg} / \mathrm{l}$ and $17 \cdot 9$ (95\% CI 16.4, 19.6) mg/l in all children, in Group A and in Group B, respectively. Geometric mean RBP in all children, in Group A and in Group B was $1 \cdot 18(95 \%$ CI $1 \cdot 14,1 \cdot 22) \mu \mathrm{mol} / 1,1 \cdot 26$ (95\% CI $1 \cdot 20,1 \cdot 33) \mu \mathrm{mol} / 1$ and $1 \cdot 12$ (95\% CI $1 \cdot 07,1 \cdot 17) \mu \mathrm{mol} / 1$, respectively, before correction. Correction increased mean RBP in Group B to $1 \cdot 26(95 \%$ CI $1 \cdot 21,1 \cdot 31) \mu \mathrm{mol} / 1$. The prevalence of vitamin A deficiency $(\mathrm{RBP}<0 \cdot 825 \mu \mathrm{mol} / \mathrm{l})$ reduced from $18 \cdot 4 \%$ (95\% CI 17.2, $23 \cdot 0 \%)$ to $13.9 \%$ (95\% CI 11.3, 16.5\%).

Conclusions: Correcting for the acute-phase response significantly reduced the prevalence of vitamin A deficiency; thus, the acute-phase response should be considered when vitamin A status is assessed using RBP in order to improve population-level estimates of vitamin A deficiency.
\end{abstract}

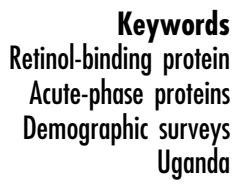

Vitamin A deficiency (VAD) is of public health significance if $15 \%$ or more of pre-school children have serum retinol concentration less than $0 \cdot 7 \mu \mathrm{mol} / \mathrm{l}^{(1,2)}$. The 2006 Uganda Demographic and Health Survey (UDHS 2006) assessed VAD in children aged 6-59 months by testing for retinolbinding protein (RBP), a surrogate of retinol, in dried blood spots (DBS) ${ }^{(3)}$. The VAD prevalence estimate in children was $20 \cdot 4 \%{ }^{(4)}$. Circulating concentrations of serum retinol ${ }^{(5-7)}$ and $\mathrm{RBP}^{(8)}$ decline in response to the acute-phase response and may not adequately reflect vitamin A status. These changes, which are an integral part of the acute-phase response, reflect decreased synthesis of RBP and increased excretion of retinol in urine ${ }^{(9,10)}$. Because levels of circulating acute-phase proteins (APP) can aid in the interpretation of low serum retinol levels, the simultaneous measurement of retinol and one or more APP is recommended ${ }^{(5-7,11-13)}$.

There is currently no consensus on how to correct retinol concentrations for the influence of the acute-phase response. Paracha et $a l^{(11)}$ proposed the application of new cut-offs for low and deficient retinol concentrations for children in whom $\alpha_{1}$-antichymotrypsin and $\alpha_{1}$-acid glycoprotein concentrations were elevated. In the approach proposed by Thurnham et al. ${ }^{(7)}$, individuals with normal APP levels provide the reference group for whom it is assumed that diet is the main factor responsible for the concentration of retinol. The median retinol value for the reference group is divided by the respective median values for groups at different stages of the acutephase response. Correction factors thus obtained were applied to apparently healthy HIV-1-positive adults with raised APP; the proportion with low plasma retinol concentration $(<0.7 \mu \mathrm{mol}$ retinol/1) was significantly reduced from $20 \%$ to $16 \%{ }^{(14)}$. Wieringa et al. ${ }^{(13)}$ recommend the application of correction factors estimated using a general linear model based on the differences in plasma retinol concentrations between individuals with normal C-reactive protein (CRP) and $\alpha_{1}$-acid glycoprotein, and those with raised CRP and $\alpha_{1}$-acid glycoprotein. 
An alternative approach is to exclude the individuals with raised APP from the analysis. However, excluding individuals with raised APP may result in sampling bias for variables such as age, gender and history of hospitalization ${ }^{(15)}$. Moreover, exclusion of individuals results in a reduced sample. Regardless of the approach, the consensus is that including measurements of APP will improve the interpretation of results when vitamin A status is assessed using retinol and RBP. The application of a correction factor is a logical approach for interpreting levels of serum retinol ${ }^{(12-14)}$ and other nutritional biomarkers ${ }^{(16-18)}$ that are influenced by infection, when these indicators are measured in populations with a high burden of infection.

We previously reported on the assessment of the prevalence of VAD in the UDHS 2006 using an enzyme immunoassay to measure the levels of RBP in $\mathrm{DBS}^{(3)}$. However, we did not measure any APP at that time. Given the extent of the burden of infection in Uganda ${ }^{(19)}$ there is a high likelihood that many of the young children who participated in UDHS 2006 had subclinical infection/ inflammation and therefore raised APP, which probably influenced the VAD prevalence estimate. We report here the effect of the acute-phase response on the VAD prevalence estimate in children in a population-level survey in Uganda using CRP as a biomarker of inflammation.

\section{Methods}

\section{Study design and participants}

The DBS samples analysed in the present study were collected as part of the UDHS 2006, which was the fourth Demographic and Health Survey to be conducted in Uganda and the first Demographic and Health Survey to cover the entire country. The study design and selection of the survey sample are described in the UDHS 2006 Report ${ }^{(4)}$. Briefly, the UDHS 2006 was a household-based survey in which a representative probability sample of 9864 households was selected from 368 clusters. Vitamin A status was assessed in one-third of the selected households. All children aged 6-59 months in these households were eligible for RBP testing. The study was conducted according to the guidelines laid down in the Declaration of Helsinki and all procedures involving human subjects were approved by the Uganda National Council for Science and Technology. Verbal informed consent for RBP testing was obtained on behalf of the children from the parent or another adult responsible for the child. Verbal consent was witnessed and formally recorded. Consent was also obtained specifically for additional tests on the $\mathrm{DBS}^{(4)}$.

\section{Sample size and selection of dried blood spots for analysis of C-reactive protein}

Blood samples were collected from a total of 2460 children (aged 6-59 months) from May to October $2006^{(3)}$.
The collection, transport and storage of the DBS were described previously ${ }^{(3)}$. Briefly, blood samples were collected at the household from eligible children by finger or heel prick. Blood drops were allowed to fall freely to fill 13-mm diameter pre-printed circles on filter paper cards (Whatman 903; GE Healthcare Ltd, Piscataway, NJ, USA). The filter paper cards were labelled and dried overnight in opaque boxes containing desiccant (Minipak; Multisorb Technologies, Buffalo, NY, USA), packed individually in low-gas-permeable plastic zip-lock bags containing desiccant and humidity indicator cards, and stored at $-20^{\circ} \mathrm{C}$ until analysis. Analysis for RBP using enzyme immunoassay (SCANLISA ${ }^{\circledR}$ RBP Assay; Scimedx Corporation, Denville, NJ, USA) was carried out in 2006 and is described elsewhere $^{(3)}$. In preparation for CRP analysis, all 2460 DBS were checked individually for stability (humidity status) and adequacy of spots. After elimination of unsuitable samples, the sample frame comprised 1554 DBS. The samples were arranged by region and every other sample was selected, giving a total of 775 samples selected. Analysis for CRP was carried out in May and June 2008.

\section{Laboratory procedures}

\section{Reagents}

CRP was determined using an in-house enzyme immunoassay $^{(20)}$ which was optimized in our laboratory before analysis of samples. The following reagents were used: capture antibody was a mouse monoclonal antibody to CRP, clone C5 (\#M86005 M, $6.5 \mathrm{mg} / \mathrm{ml}$ stock; Biodesign International, Saco, ME, USA); signal antibody was a mouse monoclonal antibody to CRP clone C6, biotin conjugated (Biodesign \#M86284B, $1.5 \mathrm{mg} / \mathrm{ml}$ stock); CRP calibrator (\#30-AC10, $2.7 \mathrm{mg} / \mathrm{ml}$; Fitzgerald Industries International, Action, MA, USA); and horseradish peroxidase (HRP)conjugated streptavidin (Invitrogen \#43-8323; Life Technologies, Grand Island, NY, USA). The following solutions were prepared using reagents from Applichem $\mathrm{GmbH}$ (Darmstadt, Germany): coating buffer $\left(0 \cdot 20 \mathrm{~m}-\mathrm{NaHCO}_{3}\right.$, pH 9.6); CRP assay buffer (0.01 m-phosphate buffer, 0.5 $\mathrm{m}-\mathrm{NaCl}, 0 \cdot 1 \%(\mathrm{v} / \mathrm{v})$ Tween $20, \mathrm{pH} 7 \cdot 2 \pm 0 \cdot 3)$; wash solution $(0.15 \mathrm{M}-\mathrm{NaCl}, 0.05 \%(\mathrm{v} / \mathrm{v})$ Tween 20$)$; and citrate buffer $(0 \cdot 05$ м, pH 4.0). 2,2'-Azino-bis(3-ethylbenzthiazoline-6sulfonic acid) (ABTS) solution was prepared by dissolving each ABTS tablet (\#9941; Sigma-Aldrich, St Louis, MO, USA) in $50 \mathrm{ml}$ of $0.05 \mathrm{~m}$-phosphate-citrate buffer, $\mathrm{pH} 5 \cdot 0$. Hydrogen peroxide $(30 \% \mathrm{v} / \mathrm{v})$ was added to the ABTS solution immediately before use $(0 \cdot 25 \mu \mathrm{l} / \mathrm{ml})$.

\section{Elution of dried blood spots for C-reactive protein}

The filter paper cards with the DBS were removed from the freezer and one disc from a blood spot on each card, corresponding to an individual child, was punched out using a standard $3.2 \mathrm{~mm}(1 / 8$ in) hole punch and placed in a micro centrifuge tube. CRP assay buffer $(500 \mu \mathrm{l})$ was added to each tube. Each $3 \cdot 2 \mathrm{~mm}$ disc 
Table 1 Validation of DBS as a matrix for CRP analysis

\begin{tabular}{|c|c|c|c|}
\hline & & Mean & $95 \% \mathrm{Cl}$ \\
\hline Correlation $(r)$ between serum CRP and DBS CRP & $0.84^{*}$ & & \\
\hline Serum CRP (mg/l) & & $0 \cdot 78$ & $0 \cdot 52,1 \cdot 16$ \\
\hline Unadjusted DBS CRP (mg/l) & & $0 \cdot 19$ & $0.14,0.25$ \\
\hline Correction factor & $4 \cdot 24$ & & \\
\hline Adjusted DBS CRP (mg/l) & & $0 \cdot 79$ & $0.60,1.06$ \\
\hline
\end{tabular}

DBS, dried blood spot; CRP, C-reactive protein.

Fifty matched DBS and serum samples.

${ }^{*} P=0.000$.

contains $\sim 1.5 \mu \mathrm{l}$ of serum $^{(21)}$; this corresponds to a dilution factor of $\sim 1: 333 \cdot 3$. The tubes were vortexed for $15 \mathrm{~s}$ and centrifuged at $5000 \mathrm{rpm}$ for $2 \mathrm{~min}$. Samples were incubated overnight at $4^{\circ} \mathrm{C}$. The following day, samples were removed from refrigeration and rotated at $350 \mathrm{rpm}$ at room temperature for $1 \mathrm{~h}$.

\section{C-reactive protein assay protocol}

Microwell plates (Nunc ${ }^{\mathrm{TM}}$ MaxiSorp; Nalge Nunc International, Rochester, NY, USA) were coated with capture antibody $(2 \mu \mathrm{g} / \mathrm{ml})$ in coating buffer $(100 \mu \mathrm{l} /$ well $)$, covered with microplate lids and incubated at $4-8^{\circ} \mathrm{C}$ for not more than $72 \mathrm{~h}$. On the day of the assay, the plates were removed from the refrigerator, washed three times with wash buffer and blocked with CRP assay buffer $(200 \mu \mathrm{l} /$ well). The plates were incubated for at least $30 \mathrm{~min}$ and for not more than $2 \mathrm{~h}$ at room temperature after which they were washed three times with wash buffer. Then, $100 \mu \mathrm{l}$ of calibrators (eight points ranging from $0 \mathrm{ng} / \mathrm{ml}$ to $20 \cdot 2 \mathrm{ng} / \mathrm{ml}$ ), eluted DBS samples and internal controls were added in duplicate to appropriate microwells. The plates were covered, rotated on a plate shaker (Stuart ${ }^{\circledR}$ SSM5 Microtitre Plate Shaker; Bibby Scientific Limited, Stone, UK) at $250 \mathrm{rpm}$ for $1 \mathrm{~min}$ and incubated overnight at $4{ }^{\circ} \mathrm{C}$. The next day, the plates were washed three times with wash buffer and then signal antibody $(500 \mathrm{ng} / \mathrm{ml})$ in CRP assay buffer $(100 \mu \mathrm{l} /$ well $)$ was added. The plates were incubated for $2 \mathrm{~h}$ at room temperature after which they were washed four times with wash buffer. HRPconjugated streptavidin diluted 1:3000 in CRP assay buffer was added $(100 \mu \mathrm{l} /$ well). After $1 \mathrm{~h}$ incubation at room temperature, $100 \mu$ l of freshly prepared substrate solution was added. The plates were shaken at $250 \mathrm{rpm}$ at room temperature for $60-90 \mathrm{~min}$ and read at $405 \mathrm{~nm}$ on a microplate reader (Sunrise ${ }^{\mathrm{TM}}$ Remote Control; Tecan Austria GmbH, Salzburg, Austria). Unknown concentrations were calculated from the best-fit four-parameter logistic standard curve (GraphPad Prism ${ }^{\circledR}$ version 3.02). An acceptable agreement between duplicates was defined as a CV of $\leq 10 \%$ between the optical densities of duplicates according to established assay acceptance criteria. Internal DBS controls and a pooled serum control were run with each plate. The inter-assay variability was $7 \cdot 4 \%$ for serum and $6 \cdot 2 \%$ for DBS. No external quality controls were included. CRP concentrations recorded as being below the lowest detectable level of the assay or higher than the limit of detection were classified as normal and raised, respectively.

\section{Validation of dried blood spots as a sample matrix for C-reactive protein}

Fifty matching serum and DBS samples collected from volunteers in June 2008 were used to validate DBS as a sample matrix for CRP analysis. Venous blood samples $(\sim 3 \mathrm{ml})$ were drawn into plain vacutainer tubes. Serum was separated by centrifugation on the day of sampling, separated into aliquots and frozen at $-20^{\circ} \mathrm{C}$ until analysis, which was carried out in the same month that the samples were collected. Matching DBS samples were collected, stored and eluted as described above. Serum was first diluted $1: 333.3(1.5 \mu \mathrm{l}$ of serum in $500 \mu \mathrm{l}$ of CRP assay buffer). Matching DBS eluate and diluted serum were loaded onto the same coated microwell plates in order to exclude potential variations that would arise from analysing matching samples on separate plates and were analysed as described above. The validation experiment demonstrated excellent correlation between CRP values of matching serum and DBS $(r=0 \cdot 84, \quad P<0 \cdot 0001)$. A factor to correct DBS CRP values to serum CRP values was derived by dividing each serum CRP value by its matching DBS CRP value. The median of the values obtained was $4 \cdot 24$; this was then used to correct all DBS CRP values. These validation data are summarized in Table 1. A similar validation experiment for RBP had already demonstrated an excellent correlation between RBP values of matching serum and DBS samples $(r=0 \cdot 79, P<0 \cdot 00001)$. A correction factor of 1.44 was used to correct all DBS RBP values ${ }^{(3)}$.

\section{Data analysis}

Logarithmic transformation of the data was performed in order to normalize the skewed distribution. The resulting values are presented in their original units. The method of applying a correction factor ${ }^{(7)}$ was used to correct RBP values for the effect of the acute-phase response. First, the children were classified as 'normal CRP' (Group A) or 'raised CRP' (Group B) on the basis of a CRP cut-off of $5 \mathrm{mg} / \mathrm{l}^{(12)}$. A correction factor of $1 \cdot 127$ was obtained as the ratio of the geometric means of the RBP concentrations of Group A to Group B (the difference between 
mean log RBP value for Group A and mean log RBP for Group B is back-transformed to give the correction factor). Group B RBP values were then multiplied by the correction factor to give the corrected RBP values. Cross-tabulation was used to obtain frequencies and proportions of children in Group A and in Group B by background characteristics and of VAD before and after correction for the influence of the acute-phase response indicated by raised CRP. Pearson's $\chi^{2}$ test was used to measure associations between CRP status and background characteristics and $P$ values less than 0.05 were considered as statistically significant. Data analysis was done using the statistical software package SPSS $13 \cdot 0$ for Windows.

\section{Results}

Seventy-three of the results were excluded after laboratory analysis because the children were aged $\geq 60$ months. A further forty-one results were excluded because of invalid results (CV between duplicates $>10 \%$ ), leaving 661 samples that were included in data analysis. As Table 2 shows, the background characteristics of the 661 children included in data analysis are comparable to those of the parent UDHS 2006 sample of the children from whom the sub-sample was drawn; except for the lowest wealth quintile which has a higher representation in the sub-sample compared with the parent sample $(24 \cdot 0 \%$ v. 20.3\%, $P=0.04$ ) and the second wealth quintile which has a lower representation in the sub-sample compared with the parent sample $(18.6 \% v .22 \cdot 5 \%, P=0.03)$.

Mean CRP was $6 \cdot 2(95 \%$ CI $5 \cdot 5,7 \cdot 0) \mathrm{mg} / \mathrm{l}$; the prevalence of raised CRP ( $>5 \mathrm{mg} / \mathrm{l})$ was $55 \cdot 7 \%$. Children in Group A had a mean CRP of 1.6 (95\% CI 1.5, 1.8) mg/l compared with $17.9(95 \%$ CI $16.4,19.6) \mathrm{mg} / 1$ for the children in Group B. As Table 3 shows, there were some differences in background characteristics between children in Group A and Group B. Group B had a higher proportion of children aged $12-23$ months $(P=0 \cdot 05)$ and a lower proportion of children aged 48-59 months $(P=0 \cdot 01)$, compared with Group A. The association between CRP status and age was significant $\left(\chi^{2}=13 \cdot 6\right.$, $P=0 \cdot 009)$. The proportion of children in Group B who live in Central 2 region was twice the proportion of children in Group A living in the same region $(12 \cdot 2 \%$

Table 2 Comparison of background characteristics of children (aged 6-59 months) between the sub-sample and the parent sample, UDHS 2006

\begin{tabular}{|c|c|c|c|c|}
\hline \multirow[b]{2}{*}{ Background characteristic } & \multicolumn{2}{|c|}{ UDHS 2006 sample } & \multicolumn{2}{|c|}{ Sub-sample } \\
\hline & Weighted \% & $95 \% \mathrm{Cl}$ & Weighted \% & $95 \% \mathrm{Cl}$ \\
\hline \multicolumn{5}{|l|}{ Age (months) } \\
\hline $6-11$ & $10 \cdot 9$ & $9 \cdot 7,12 \cdot 1$ & $9 \cdot 5$ & $7 \cdot 3,11 \cdot 7$ \\
\hline $12-23$ & $23 \cdot 5$ & $21 \cdot 8,25 \cdot 2$ & $24 \cdot 9$ & $21 \cdot 6,28 \cdot 2$ \\
\hline $24-35$ & $21 \cdot 7$ & $20 \cdot 1,23 \cdot 3$ & $22 \cdot 0$ & $18 \cdot 8,25 \cdot 2$ \\
\hline $36-47$ & $21 \cdot 8$ & $20 \cdot 2,23 \cdot 4$ & $19 \cdot 9$ & $16 \cdot 9,22 \cdot 9$ \\
\hline $48-59$ & $22 \cdot 1$ & $20 \cdot 5,23 \cdot 7$ & $23 \cdot 7$ & $20 \cdot 5,26 \cdot 9$ \\
\hline \multicolumn{5}{|l|}{ Residence } \\
\hline Urban & $9 \cdot 7$ & $8 \cdot 5,10 \cdot 9$ & $9 \cdot 2$ & $7 \cdot 0,11 \cdot 4$ \\
\hline Rural & $90 \cdot 3$ & $89 \cdot 1,91 \cdot 5$ & $90 \cdot 8$ & $88 \cdot 6,93 \cdot 0$ \\
\hline \multicolumn{5}{|l|}{ Region } \\
\hline Central 1 & $10 \cdot 3$ & $9 \cdot 1,11 \cdot 5$ & $9 \cdot 6$ & $7 \cdot 4,11 \cdot 8$ \\
\hline Central 2 & $9 \cdot 3$ & $8 \cdot 2,10 \cdot 4$ & $9 \cdot 4$ & $7 \cdot 2,11 \cdot 6$ \\
\hline Kampala & $4 \cdot 7$ & $3 \cdot 9,5 \cdot 5$ & $4 \cdot 4$ & $2 \cdot 8,6 \cdot 0$ \\
\hline East Central & $11 \cdot 6$ & $10 \cdot 3,12 \cdot 9$ & $12 \cdot 2$ & $9 \cdot 7,14 \cdot 7$ \\
\hline Eastern & $15 \cdot 2$ & $13 \cdot 8,16 \cdot 6$ & $15 \cdot 0$ & $12 \cdot 3,17 \cdot 7$ \\
\hline North & $14 \cdot 8$ & $13 \cdot 4,16 \cdot 2$ & $16 \cdot 3$ & $13 \cdot 5,19 \cdot 1$ \\
\hline West Nile & $5 \cdot 5$ & $4 \cdot 6,6 \cdot 4$ & $5 \cdot 3$ & $3 \cdot 6,7 \cdot 0$ \\
\hline Western & $15 \cdot 5$ & $14 \cdot 1,16 \cdot 9$ & $14 \cdot 5$ & $11 \cdot 8,17 \cdot 2$ \\
\hline Southwest & $13 \cdot 1$ & $11 \cdot 8,14 \cdot 4$ & $13 \cdot 3$ & $10 \cdot 7,15 \cdot 9$ \\
\hline \multicolumn{5}{|l|}{ Mother's education } \\
\hline None & $23 \cdot 1$ & $21 \cdot 4,24 \cdot 8$ & $22 \cdot 9$ & $19 \cdot 7,26 \cdot 1$ \\
\hline Primary & $64 \cdot 1$ & $62 \cdot 2,66 \cdot 0$ & $63 \cdot 4$ & $59 \cdot 7,67 \cdot 1$ \\
\hline Secondary or higher & $12 \cdot 8$ & $11 \cdot 5,14 \cdot 1$ & $13 \cdot 7$ & $11 \cdot 1,16 \cdot 3$ \\
\hline \multicolumn{5}{|l|}{ Wealth quintile } \\
\hline Lowest & $20 \cdot 3^{*}$ & $18 \cdot 7,21 \cdot 9$ & $23 \cdot 9^{\star}$ & $20 \cdot 7,27 \cdot 1$ \\
\hline Second & $22 \cdot 5^{\star}$ & $20 \cdot 9,24 \cdot 1$ & $18 \cdot 6^{*}$ & $15 \cdot 6,21 \cdot 6$ \\
\hline Middle & $21 \cdot 4$ & $19 \cdot 8,23 \cdot 0$ & $21 \cdot 5$ & $18 \cdot 4,24 \cdot 6$ \\
\hline Fourth & $19 \cdot 0$ & $17 \cdot 5,20 \cdot 5$ & $21 \cdot 8$ & $18 \cdot 7,24 \cdot 9$ \\
\hline Highest & $16 \cdot 7$ & $15 \cdot 2,18 \cdot 2$ & $14 \cdot 2$ & $11 \cdot 5,16 \cdot 9$ \\
\hline Total & 2466 & & 661 & \\
\hline
\end{tabular}

UDHS 2006, 2006 Uganda Demographic and Health Survey,

Seventy-three of the 775 results were excluded after laboratory analysis because the children were aged $\geq 60$ months. A further forty-one results were excluded because of invalid results (CV between duplicates $>10 \%$ ), leaving 661 samples.

The difference between the parent UDHS sample and the sub-sample was significant: ${ }^{\star} P<0.05$. 
Table 3 Background characteristics of children (aged 6-59 months) with normal CRP ( $<5 \mathrm{mg} / \mathrm{l}$, Group A) and raised CRP ( $\geq 5 \mathrm{mg} / \mathrm{l}$, Group B), UDHS 2006

\begin{tabular}{|c|c|c|c|c|c|c|}
\hline \multirow[b]{2}{*}{ Background characteristic } & \multicolumn{2}{|c|}{ Group A } & \multicolumn{2}{|c|}{ Group B } & \multirow[b]{2}{*}{$\chi^{2}$} & \multirow[b]{2}{*}{$P$} \\
\hline & Weighted \% & $95 \% \mathrm{Cl}$ & Weighted \% & $95 \% \mathrm{Cl}$ & & \\
\hline \multicolumn{7}{|l|}{ Age (months) } \\
\hline $6-11$ & $7 \cdot 9$ & $4 \cdot 8,11 \cdot 0$ & $10 \cdot 8$ & $7 \cdot 7,14 \cdot 0$ & & \\
\hline $12-23$ & $20 \cdot 5^{\star}$ & $15 \cdot 9,25 \cdot 2$ & $28 \cdot 5^{\star}$ & $23 \cdot 9,33 \cdot 1$ & & \\
\hline $24-35$ & $21 \cdot 9$ & $17 \cdot 2,26 \cdot 7$ & $22 \cdot 0$ & $17 \cdot 7,26 \cdot 2$ & $13 \cdot 63$ & 0.009 \\
\hline $36-47$ & $19 \cdot 9$ & $15 \cdot 3,24 \cdot 4$ & $19 \cdot 8$ & $15 \cdot 7,23 \cdot 8$ & & \\
\hline $48-59$ & $29 \cdot 8^{\star \star}$ & $24 \cdot 5,35 \cdot 0$ & $19 \cdot 0^{\star \star}$ & $15 \cdot 0,23 \cdot 0$ & & \\
\hline \multicolumn{7}{|l|}{ Residence } \\
\hline Urban & $11 \cdot 6$ & $7 \cdot 9,15 \cdot 3$ & $7 \cdot 3$ & $4 \cdot 7,10 \cdot 0$ & $3 \cdot 59$ & 0.058 \\
\hline Rural & $88 \cdot 4$ & $84 \cdot 7,92 \cdot 1$ & $92 \cdot 7$ & $90 \cdot 0,95 \cdot 3$ & & \\
\hline \multicolumn{7}{|l|}{ Region } \\
\hline Central 1 & $12 \cdot 2^{*}$ & $8 \cdot 5,16 \cdot 0$ & $7 \cdot 6^{\star}$ & $4 \cdot 9,10 \cdot 3$ & & \\
\hline Central 2 & $6 \cdot 1^{\star \star \star}$ & $3 \cdot 4,8 \cdot 9$ & $12 \cdot 2^{\star \star \star}$ & $8 \cdot 9,15 \cdot 5$ & & \\
\hline Kampala & $4 \cdot 1$ & $1 \cdot 8,6 \cdot 3$ & $4 \cdot 3$ & $2 \cdot 3,6 \cdot 4$ & & \\
\hline East Central & $12 \cdot 9$ & $9 \cdot 1,16 \cdot 8$ & $11 \cdot 7$ & $8 \cdot 4,14 \cdot 9$ & & \\
\hline Eastern & $14 \cdot 6$ & $10 \cdot 6,18 \cdot 7$ & $15 \cdot 4$ & $11 \cdot 8,19 \cdot 1$ & $15 \cdot 79$ & 0.045 \\
\hline North & $16 \cdot 0$ & $11 \cdot 8,20 \cdot 2$ & $16 \cdot 5$ & $12 \cdot 7,20 \cdot 3$ & & \\
\hline West Nile & $3 \cdot 4^{*}$ & $1 \cdot 3,5 \cdot 5$ & $6 \cdot 8^{\star}$ & $4 \cdot 2,9 \cdot 3$ & & \\
\hline Western & $15 \cdot 3$ & $11 \cdot 2,19 \cdot 4$ & $13 \cdot 8$ & $10 \cdot 3,17 \cdot 3$ & & \\
\hline Southwest & $15 \cdot 3$ & $11 \cdot 2,19 \cdot 4$ & $11 \cdot 7$ & $8 \cdot 4,14 \cdot 9$ & & \\
\hline \multicolumn{7}{|l|}{ Mother's education } \\
\hline None & $18 \cdot 1^{\star \star *}$ & $13 \cdot 7,22 \cdot 5$ & $26 \cdot 9^{\star \star \star}$ & $22 \cdot 4,31 \cdot 4$ & & \\
\hline Primary & $65 \cdot 2$ & $59 \cdot 7,70 \cdot 6$ & $62 \cdot 0$ & $57 \cdot 0,66 \cdot 9$ & $9 \cdot 51$ & 0.009 \\
\hline Secondary or higher & $16 \cdot 7^{\star}$ & $12 \cdot 5,21 \cdot 0$ & $11 \cdot 1^{*}$ & $7 \cdot 9,14 \cdot 4$ & & \\
\hline \multicolumn{7}{|l|}{ Wealth quintile } \\
\hline Lowest & $20 \cdot 8$ & $16 \cdot 2,25 \cdot 5$ & $26 \cdot 4$ & $21 \cdot 9,30 \cdot 9$ & & \\
\hline Second & $17 \cdot 7$ & $13 \cdot 4,22 \cdot 1$ & $19 \cdot 3$ & $15 \cdot 3,23 \cdot 3$ & & \\
\hline Middle & $20 \cdot 8$ & $16 \cdot 2,25 \cdot 5$ & $22 \cdot 0$ & $17 \cdot 8,26 \cdot 2$ & $5 \cdot 96$ & $0 \cdot 20$ \\
\hline Fourth & $23 \cdot 9$ & $19 \cdot 0,28 \cdot 8$ & $20 \cdot 4$ & $16 \cdot 3,24 \cdot 5$ & & \\
\hline Highest & $16 \cdot 7$ & $12 \cdot 5,21 \cdot 0$ & $12 \cdot 0$ & $8 \cdot 6,15 \cdot 3$ & & \\
\hline Number of children & 293 & & 368 & & & \\
\hline
\end{tabular}

CRP, C-reactive protein; UDHS 2006, 2006 Uganda Demographic and Health Survey.

Seventy-three of the 775 results were excluded after laboratory analysis because the children were aged $\geq 60$ months. A further forty-one results were excluded because of invalid results (CV between duplicates $>10 \%$ ), leaving 661 samples.

The difference between Group A and Group B was significant: ${ }^{\star} P=0 \cdot 05,{ }^{\star \star} P=0 \cdot 01,{ }^{\star \star \star} P=0 \cdot 001$.

(95\% CI $8 \cdot 9, \quad 15 \cdot 5 \%) \quad v \cdot 6 \cdot 1 \%(95 \%$ CI $3 \cdot 4,8 \cdot 9 \%)$ $P<0.001)$. The association between CRP status and mother's education status was significant $\left(\chi^{2}=9 \cdot 5\right.$, $P=0 \cdot 009)$; the proportion of children in Group B whose mothers had no formal education was significantly higher than the proportion of children in Group A whose mothers had no formal education $(26.9 \%$ (95\% CI $22 \cdot 4$, $31 \cdot 4 \%)$ v. $18 \cdot 1 \%(95 \%$ CI $13 \cdot 7,22 \cdot 5 \%) ; P<0 \cdot 001)$. There was no association with wealth quintile.

Figure 1 shows the mean RBP values of the children before and after correction for the acute-phase response. Geometric mean RBP of the whole group and of Group B before correction was $1 \cdot 18$ (95\% CI $1 \cdot 14,1 \cdot 22) \mu \mathrm{mol} / 1$ and $1 \cdot 12(95 \%$ CI $1 \cdot 07,1 \cdot 17) \mu \mathrm{mol} / 1$, respectively. Both were significantly different from geometric mean RBP of Group A $(1.26 \mu \mathrm{mol} / 1 ; 95 \% \mathrm{CI} 1 \cdot 20,1.33 \mu \mathrm{mol} / \mathrm{l})$. After correction, geometric mean RBP of Group B $(1.26 \mu \mathrm{mol} / 1 ; 95 \%$ CI $1 \cdot 21$, $1.31 \mu \mathrm{mol} / \mathrm{l})$ and of the whole group ( $1.26 \mu \mathrm{mol} / \mathrm{l} ; 95 \% \mathrm{CI}$ $1 \cdot 22,1 \cdot 30 \mu \mathrm{mol} / \mathrm{l})$ were not significantly different from geometric mean RBP of Group A.

The recommended cut-off for VAD of $0.7 \mu \mathrm{mol} / \mathrm{l}$ of serum retinol ${ }^{(2)}$ is taken to be biologically equivalent to $0.825 \mu \mathrm{mol} / 1 \mathrm{RBP}^{(22)}$. Using this cut-off, the prevalence of VAD in Group B before correction (22.0\%; $95 \%$ CI $17 \cdot 8$,

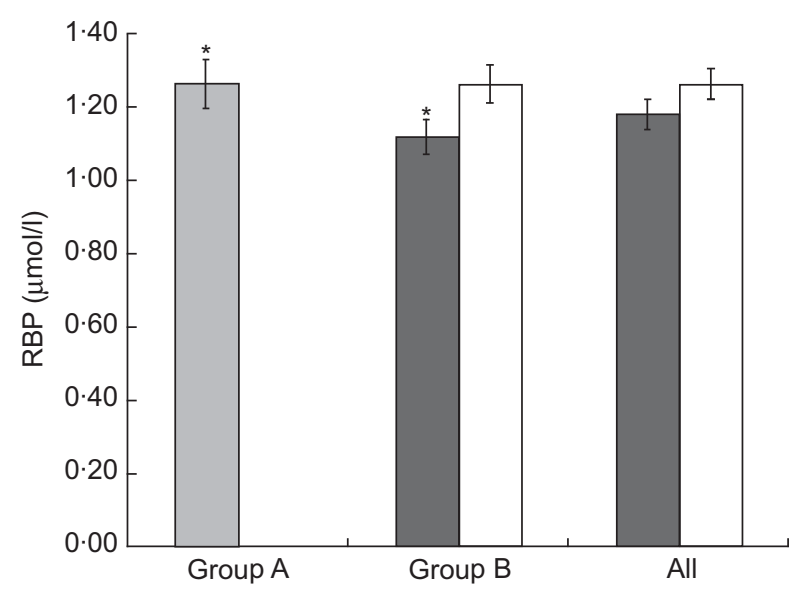

Fig. 1 Retinol-binding protein (RBP) in children (aged 6-59 months, $n$ 661) before $(\square)$ and after correction $(\square)$ for the influence of the acute-phase response, 2006 Uganda Demographic and Health Survey. Values are geometric means, with $95 \%$ confidence intervals represented by vertical bars. The difference in mean RBP of Group A ( $n$ 293) and Group B ( $n$ 368) before correction was significant: ${ }^{*} P<0.0001$

$26 \cdot 2 \%)$ was higher than the prevalence of VAD in Group A (14.7\%; 95\% CI 10.6, 18.8\%). After correction, the prevalence of VAD in Group B $(13 \cdot 3 \%$; $95 \%$ CI $9 \cdot 8$, 
$16 \cdot 8 \%)$ was comparable to the prevalence of VAD in Group A. In addition, the prevalence of VAD among all of the children after correction (13.9\%; $95 \%$ CI 11.3, 16.5\%) was not significantly different from the prevalence of VAD in Group A. After correction the prevalence of VAD among all children was reduced from $18.4 \%$ (95\% CI $17 \cdot 2,23 \cdot 0 \%)$ to $13 \cdot 9 \%(95 \%$ CI $11 \cdot 3,16 \cdot 5 \%)$, which is just below the cut-off of $15 \%$ at which VAD is deemed to be a public health problem. Out of 125 children with VAD and raised CRP, thirty-three changed status from VAD to vitamin A sufficiency after correction, representing a reduction of about $25 \%$. On the basis of these findings, we postulate that the prevalence of VAD would reduce by at least $25 \%$ from $20 \cdot 1 \%$ to $15 \cdot 4 \%$.

\section{Discussion}

The overall aim of the present study was to determine if the estimate of the prevalence of VAD in children of pre-school age in the 2006 UDHS was distorted by the influence of the acute-phase response on RBP and to improve this estimate by correcting RBP measurements for the effect of the acute-phase response. The results show that over half of this population-based sub-sample of children had raised CRP. The group with raised CRP had a significantly lower mean RBP and a significantly higher prevalence of VAD compared with the group with normal CRP levels. The same effect has been demonstrated in several other studies in children ${ }^{(5,7,11-13,23,24)}$. After correction of the RBP values, the two groups had a comparable mean RBP and prevalence of VAD, and the overall prevalence of VAD of the sub-sample was significantly reduced. Given that the children with raised CRP constituted over half of the sub-sample and that the sub-sample was generally representative of the parent UDHS 2006 sample, we postulate that the prevalence of VAD reported in the UDHS 2006 could have been overestimated by as much as $25 \%$, which is the proportion by which VAD was overestimated in the present study. Effect sizes of similar magnitude have been reported ${ }^{(7)}$.

Our findings add to the body of evidence of the high rate of subclinical infection/inflammation in children who participate in population-based surveys in settings with a high burden of disease: the proportion of apparently healthy pre-school children with one or more raised APP was $45 \%$ in the North West Frontier Province in Pakistan $^{(11)}, 57 \%$ in the Ghana Vitamin A Supplementation Trial ${ }^{(5)}$ and $24 \%$ in the 1996 National Nutrition Survey in Honduras ${ }^{(25)}$. The data used in the meta-analysis by Thurnham and colleagues show that the rate of raised APP in apparently healthy pre-school children ranged from $17 \%$ in the UK to $72 \%$ in Ghana ${ }^{(7)}$.

There were some differences in background characteristics between children in Group A and Group B. Group B had a lower proportion of children aged 48-59 months and a higher proportion of children aged 12-23 months compared with Group A, reflecting the higher vulnerability to infection of children in this age group. These findings are substantiated by the UDHS 2006, which shows that children aged 6-11 and 12-23 months were most likely to have shown symptoms of acute respiratory infection and to have had fever and diarrhoea than children in other age groups ${ }^{(4)}$. The proportion of children whose mothers had no formal education was significantly higher in Group B than it was in Group A. Again, the UDHS 2006 confirms that children whose mothers did not have any formal education were most likely to have shown symptoms of acute respiratory infection and to have had fever and diarrhoea in the two weeks preceding the survey ${ }^{(4)}$. We re-emphasize the observation made by Maqsood et al. ${ }^{(15)}$ that excluding children with raised APP is not a suitable approach for estimating the prevalence of VAD in settings such as ours because it leads to sampling bias and to a substantially reduced sample.

A limitation of using DBS is that the composition of the eluate cannot be equated to serum or plasma and elution of the biomarker of interest may not be complete ${ }^{(26)}$, thus making interpretation of results from DBS samples a challenge. Nevertheless, the significant linear correlation between matched serum and DBS samples for many analytes $^{(3,20,27-30)}$ implies that serum or plasma equivalents can be derived from DBS values ${ }^{(3,28,30-33)}$. It is on this basis that we derived a value of $4 \cdot 24$ to correct the DBS CRP values to serum CRP values. However, the relationship between DBS values and plasma or serum values varies across analytic methods ${ }^{(26,27)}$, meaning that we are able to evaluate our correction factor relative only to Brindle et al. ${ }^{(20)}$ who used the same in-house enzyme immunoassay. The volume they used to elute their DBS ranged from $0 \cdot 25$ to $5 \mathrm{ml}$ making their mean ratio of DBS CRP (venous or capillary) to serum CRP of 1.6 difficult to interpret relative to ours. Also to consider is haematocrit ${ }^{(21)}$, which has been identified as the single most important parameter that influences the spread of blood on DBS cards, ultimately affecting the reproducibility of assays especially when a sub-sample punch is taken from the $\mathrm{DBS}^{(34)}$. The majority of the individuals in the study done by Brindle and colleagues were US adults ${ }^{(20)}$ who are reported to have higher haematocrit than Africans ${ }^{(35,36)}$. This further complicates the interpretation of their mean ratio of DBS CRP to serum CRP relative to ours and indicates that these correction factors cannot be applied universally.

A correction factor of $1 \cdot 127$ was obtained and used to adjust the RBP values of Group B. A meta-analysis of three studies with a total of 1797 apparently healthy pre-school children aged $1-5$ years generated an adjustment factor of $1 \cdot 25^{(7)}$. Using this factor to adjust the RBP values of Group B gives a mean RBP of 1.40 (95\% CI $1 \cdot 34,1 \cdot 46) \mu \mathrm{mol} / \mathrm{l}$, which is significantly higher than the 
mean RBP of the children with normal CRP (1.26 (95\% CI $1 \cdot 20,1 \cdot 33) \mu \mathrm{mol} / 1)$. Thurnham and colleagues also found that specific correction factors derived from the data of a particular group of individuals are more effective than the meta-analysis correction factors ${ }^{(12,14)}$.

Although CRP has been recommended as a reasonable choice of APP for interpreting the influence of the acutephase response in the assessment of vitamin A status ${ }^{(37)}$, it is only elevated during the earlier, clinical stages of infection $^{(38,39)}$. Consequently, in measuring only CRP we may have underestimated the size of the effect of the acute-phase response on RBP. Despite the limitation of not including a marker of chronic infection in the current study, our findings demonstrate the utility of adjusting RBP levels for the effect of the acute-phase response. The results strongly suggest that by not adjusting for the acutephase response, the prevalence of VAD in the UDHS 2006 was overestimated. Taking acute-phase response into account improves the population-level assessment of vitamin A status and allows a better comparison between populations with different rates of infection. Longitudinal studies will increase our understanding of the relationship between APP and micronutrient biomarkers. As more surveys incorporate nutritional biomarker measurement using DBS as the sample, there is a need to standardize the laboratory methods involved and to establish a proficiency testing programme.

\section{Acknowledgements}

Sources of funding: The 2006 UDHS was conducted by the Uganda Bureau of Statistics. Laboratory consumables, reagents, equipment and technical assistance were provided by the US Agency for International Development (USAID). Additional financial assistance for the UDHS 2006 was also provided by the UK Department of International Development, the USAID/Uganda Mission, the President's Emergency Plan for AIDS Relief, the Government of Uganda, the Health Partnership Fund, UNICEF, the United Nations Population Fund and the Government of Japan. Laboratory consumables, reagents, equipment and technical assistance for the supplemental CRP testing were provided by the USAID through ICF Macro International. Conflicts of interest: The authors do not have any conflict of interest to declare. Authors' contributions: R.B. and D.G. designed the study; R.B. and D.M.-K. conducted the laboratory analyses; R.B. carried out data analysis, interpretation and drafted the manuscript; D.M.-K. and D.G. made major revisions to the manuscript and all authors approved it for submission. Acknowledgements: The authors acknowledge and are grateful to Eleanor Brindle, CSDE Biodemography Core, University of Washington, for the CRP protocol; and thank all of the women and children of Uganda who participated in the UDHS 2006. They are grateful to the following individuals and institutions: the field technicians, field supervisors, Andrew Mukulu, Helen Nviiri and Stephen Baryahirwa, all of the Uganda Bureau of Statistics; Fred Juuko of the Department of Biochemistry, Makerere University; and Joy Fishel of ICF Macro International. The authors appreciate the reviewers' comments which enhanced the quality of the manuscript.

\section{References}

1. de Pee S \& Dary O (2002) Biochemical indicators of vitamin A deficiency: serum retinol and serum retinol binding protein. J Nutr 132, 9 Suppl., 2895S-2901S.

2. Sommer A \& Davidson FR (2002) Assessment and control of vitamin A deficiency: the Annecy Accords. J Nutr 132, 9 Suppl., 2845S-2850S.

3. Baingana RK, Matovu DK \& Garrett D (2008) Application of retinol-binding protein enzyme immunoassay to dried blood spots to assess vitamin A deficiency in a populationbased survey: the Uganda Demographic and Health Survey 2006. Food Nutr Bull 29, 297-305.

4. Uganda Bureau of Statistics \& Macro International (2007) Uganda Demographic and Health Survey, 2006. Calverton, MD: Uganda Bureau of Statistics and Macro International.

5. Filteau SM, Morris SS, Abbott RA et al. (1993) Influence of morbidity on serum retinol of children in a community-based study in northern Ghana. Am J Clin Nutr 58, 192-197.

6. Christian P, Schulze K, Stoltzfus RJ et al. (1998) Hyporetinolemia, illness symptoms, and acute phase protein response in pregnant women with and without night blindness. Am J Clin Nutr 67, 1237-1243.

7. Thurnham DI, McCabe GP, Northrop-Clewes CA et al. (2003) Effects of subclinical infection on plasma retinol concentrations and assessment of prevalence of vitamin A deficiency: meta-analysis. Lancet 362, 2052-2058.

8. Baeten JM, Richardson BA, Bankson DD et al. (2004) Use of serum retinol-binding protein for prediction of vitamin A deficiency: effects of HIV-1 infection, protein malnutrition, and the acute phase response. Am J Clin Nutr 79, 218-225.

9. Mitra AK, Alvarez JO, Wahed MA et al. (1998) Predictors of serum retinol in children with shigellosis. Am J Clin Nutr 68, 1088-1094.

10. Mitra AK, Alvarez JO, Guay-Woodford L et al. (1998) Urinary retinol excretion and kidney function in children with shigellosis. Am J Clin Nutr 68, 1095-1103.

11. Paracha PI, Jamil A, Northrop-Clewes CA et al. (2000) Interpretation of vitamin A status in apparently healthy Pakistani children by using markers of subclinical infection. Am J Clin Nutr 72, 1164-1169.

12. Thurnham DI, Mburu AS, Mwaniki DL et al. (2005) Micronutrients in childhood and the influence of subclinical inflammation. Proc Nutr Soc 64, 502-509.

13. Wieringa FT, Dijkhuizen MA, West CE et al. (2002) Estimation of the effect of the acute phase response on indicators of micronutrient status in Indonesian infants. J Nutr 132, 3061-3066.

14. Thurnham DI, Mburu AS, Mwaniki DL et al. (2008) Using plasma acute-phase protein concentrations to interpret nutritional biomarkers in apparently healthy HIV-1-seropositive Kenyan adults. Br J Nutr 100, 174-182.

15. Maqsood M, Dancheck B, Gamble MV et al. (2004) Vitamin A deficiency and inflammatory markers among preschool children in the Republic of the Marshall Islands. Nutr J 3, 21.

16. Mburu AS, Thurnham DI, Mwaniki DL et al. (2008) The influence and benefits of controlling for inflammation on plasma ferritin and hemoglobin responses following a multi-micronutrient supplement in apparently healthy, HIV + Kenyan adults. J Nutr 138, 613-619. 
17. Thurnham DI, McCabe LD, Haldar S et al. (2010) Adjusting plasma ferritin concentrations to remove the effects of subclinical inflammation in the assessment of iron deficiency: a meta-analysis. Am J Clin Nutr 92, 546-555.

18. Mburu AS, Thurnham DI, Mwaniki DL et al. (2010) The influence of inflammation on plasma zinc concentration in apparently healthy, HIV + Kenyan adults and zinc responses after a multi-micronutrient supplement. Eur J Clin Nutr 64, 510-517.

19. Ministry of Health (2005) Health Sector Strategic Plan II 2005/06-2009/10. Kampala: Ministry of Health.

20. Brindle E, Fujita M, Shofer J et al. (2010) Serum, plasma, and dried blood spot high-sensitivity C-reactive protein enzyme immunoassay for population research. J Immunol Methods 362, 112-120.

21. Mei JV, Alexander JR, Adam BW et al. (2001) Use of filter paper for the collection and analysis of human whole blood specimens. J Nutr 131, issue 5, 1631S-1636S.

22. Gorstein JL, Dary O, Pongtorn et al. (2008) Feasibility of using retinol-binding protein from capillary blood specimens to estimate serum retinol concentrations and the prevalence of vitamin A deficiency in low-resource settings. Public Health Nutr 11, 513-520.

23. Kongsbak K, Wahed MA, Friis H et al. (2006) Acute-phase protein levels, diarrhoea, Trichuris trichiura and maternal education are predictors of serum retinol: a cross-sectional study of children in a Dhaka slum, Bangladesh. BrJ Nutr 96, 725-734.

24. Filteau SM, Morris SS, Raynes JG et al. (1995) Vitamin A supplementation, morbidity, and serum acute-phase proteins in young Ghanaian children. Am J Clin Nutr 62, 434-438.

25. Nestel P, Melara A, Rosado J et al. (1999) Vitamin A deficiency and anemia among children 12-71 months old in Honduras. Rev Panam Salud Publica 6, 34-43.

26. McDade TW, Williams S \& Snodgrass JJ (2007) What a drop can do: dried blood spots as a minimally invasive method for integrating biomarkers into population-based research. Demography 44, 899-925.

27. Williams SR \& McDade TW (2009) The use of dried blood spot sampling in the national social life, health, and aging project. J Gerontol B Psychol Sci Soc Sci 64, Suppl. 1, i131-i136.

28. McDade TW, Burhop J \& Dohnal J (2004) High-sensitivity enzyme immunoassay for C-reactive protein in dried blood spots. Clin Chem 50, 652-654.

29. Kapur S, Kapur S \& Zava D (2008) Cardiometabolic risk factors assessed by a finger stick dried blood spot method. J Diabetes Sci Technol 2, 236-241.

30. Shirtcliff EA, Reavis R, Overman WH et al. (2001) Measurement of gonadal hormones in dried blood spots versus serum: verification of menstrual cycle phase. Horm Behav 39, 258-266.

31. Craft NE (2001) Innovative approaches to vitamin A assessment. J Nutr 131, issue 5, 1626S-1630S.

32. Uganda Bureau of Statistics \& ORC Macro (2001) Uganda Demographic and Health Survey, 2000-2001. Calverton, MD: Uganda Bureau of Statistics and ORC Macro.

33. McDade TW \& Shell-Duncan B (2002) Whole blood collected on filter paper provides a minimally invasive method for assessing human transferrin receptor level. J Nutr 132, 3760-3763.

34. Timmerman P, White S, Globig S et al. (2011) EBF recommendation on the validation of bioanalytical methods for dried blood spots. Bioanalysis 3, 1567-1575.

35. Karita E, Ketter N, Price MA et al. (2009) CLSI-derived hematology and biochemistry reference intervals for healthy adults in eastern and southern Africa. PLoS One 4, e4401.

36. Zeh C, Amornkul PN, Inzaule S et al. (2011) Populationbased biochemistry, immunologic and hematological reference values for adolescents and young adults in a rural population in Western Kenya. PLoS One 6, e21040.

37. Stephensen CB \& Gildengorin G (2000) Serum retinol, the acute phase response, and the apparent misclassification of vitamin A status in the third National Health and Nutrition Examination Survey. Am J Clin Nutr 72, 1170-1178.

38. Young B, Gleeson M \& Cripps AW (1991) C-reactive protein: a critical review. Acute phase response. Pathology 23, 118-124.

39. Cruickshank AM, Hansell DT, Burns HJ et al. (1989) Effect of nutritional status on acute phase protein response to elective surgery. BrJ Surg 76, 165-168. 